\title{
ALLEGORY AND SYMBOLICS IN THE ARTWORKS OF LEONARDO DA VINCI.
}

\author{
Professor Raisa Musat \\ Docent Sergey Yamaletdinov \\ Siberian Federal University, Russia
}

\begin{abstract}
The study is aimed at revealing the deep meanings inherent in the artwork "Adoration of the Magi" by Leonardo da Vinci with the help of the system of the artistic universalism. The main methods used are comparative-historical, structural-semantic, iconological and formal analysis. A special role was assigned to the practical definition of the inner design concealed by the artist in various symbolic images. On the example of the worksketch "Adoration of the Magi" is made a comparison of the images with the mythology of Antiquity, the semantics of the ancient signs, as well as with allegorical symbols, presented in the philosophical writings of Plato. The thoughts of the Renaissance are captured in the works of Leonardo da Vinci and open the way to understanding the priority ideas of the thinker-artist and the meanings of the culture of Italy XV-XVI centuries. It is assumed that the ideas of Plato aroused interest in Leonardo da Vinci, since the artworks show the method of philosophical allegories, similar to the style and symbolism in the dialogues of Plato. The analysis of Leonardo da Vinci's artworks reveals an innovative approach based on the use of a multilayered connection of artistic techniques: 1) the combination of different artistic styles reflecting the path of transformation from symbolism to realism and mannerism; 2) the inclusions of mythological, Christian symbols, allegorical comparisons. Revealing the semantics of images arranges integrity in understanding of the content and the hidden philosophical meanings in the sketch "Adoration of the Magi" and other artworks of Leonardo da Vinci. In general, the system study expands the view of the wise depth of extraordinary ideas, the specificity of artistic universalism in the artist's work. Leonardo's vision of the world is based on his own principle of "reasonable harmony". This is visibly embodied in the inclusiveness of the master's views, in the inimitability of his pictorial and graphic handwriting, in different themes and stylistics of artistic forms. Also in the artist's creativity intersect artistic traditions from different eras and styles: Antiquity, the Middle Ages, Renaissance, Mannerism Classicism, Realism. At the same time, Leonardo da Vinci can be called the harbinger of the impressionistic approach, expressed in his works in the transmission of aerial perspective in landscapes. The culmination in the works of Leonardo da Vinci is reduced to the basic vectors of human rebirth, leading to a truly spiritual renewal through communion with the divine.
\end{abstract}

Keywords: artistic and figurative system of art of the Renaissance, artistic synthesis, artistic and figurative transformation, methods of symbolization and allegory, system analysis, realism, mannerism.

\section{INTRODUCTION}

The article is aimed at an attempt to reveal a complex system of artistic language in the works of Leonardo da Vinci, combining different symbolic and semantic content. An important message is to determine the historical, cultural, artistic and semantic contexts associated with the Italian Renaissance and the priorities in the worldview of the artist 
himself. To achieve this goal, a number of approaches are used: socio-cultural, philosophical and ideological, artistic and aesthetic, and the main methods: comparative historical, structural and semantic, iconological and formal analysis.

With the return of traditions of Antiquity to the culture of Italy and in the Renaissance in a renewed quality, the system of perception of the world is changing significantly. The severity and limitation of medieval religious consciousness begins to recede: the worldview is transformed and expanded by the new views of man on himself, the organization of society, the world surrounding Nature and the Universe. Anthropocentrism and anthropomorphism in union with naturalistic pantheism more and more conquer the space of culture and art. The organic connection between man and Nature, inherent in the mythological consciousness of Antiquity, is implicitly introduced into the previously formed system of artistic representations about religious postulates, breaking the usual canons, medieval asceticism and worldly scholasticism. Therefore, in the art of the Renaissance, we see the reading of the famous ancient mythological subjects in a new artistic and stylistic interpretation. Simultaneously, the ancient symbolic images become actual, the decoding of which reveals the vital universal meanings before us. In general, the art of the Renaissance was filled with a variety of symbolic and artistic worlds, where images acquire a pronounced allegorical sound. At the same time, the era is marked by a new appeal to the ideas of Plato and the philosophy of the Neoplatonists. The name and philosophy of Plato become fundamental to the Platonic Academy in Florence (1462). He is called "God among philosophers." Allegorical symbolism in the Renaissance is also similar with the method of Plato, which was used by the wise philosopher in Antiquity in conveying "the truth as a theory and as a myth" [1]. This method was intended, firstly, to conceal heretical thoughts (we recall the fate of Socrates) and, secondly, to give live expressiveness to the content in the famous dialogues of Plato. Similar techniques of allegory are also found in the works of Leonardo da Vinci. Thus, his artistic prose, thanks to allegory, is differed by the accuracy of thought, the acuity of the sensory perception of life events. The prose is based on three genres: the oldest fable, Renaissance facetiae and unique riddles-predictions. In turn, different researchers of Leonardo's work talk about the mysteries of symbolism in his paintings. Such mysteriousness points to the unique wisdom of the master. It should be remembered that formally Leonardo da Vinci is not regarded as a philosopher of the Renaissance. However, his writings reveal the master's interest in the breadth of knowledge, an inquisitive look at ordinary things. The aspiration for the depth of comprehension of the world allowed Leonardo to anticipate the future. The works open the way for us to understand the priority interests and ideas of not only the thinker-artist himself, but also provide an opportunity to deeper reveal the socio-cultural meanings in the life of Italy in the transition period from the XV to the XVI centuries.

G. Vasari claims that Leonardo da Vinci was fascinated by the "philosophy of natural phenomena" and "created in his mind a heretical view of things not agreed with any religion, preferring to be a philosopher, not a Christian" [2]. The natural experiments, which make a significant contribution to the systematization of natural science knowledge, serve as a support for the formation of a universal view of the world. It is the research approach that changes his attitude to the ideas existed in the Middle Ages that the outer space revolves around the Earth and obeys its rhythm. From the standpoint of Leonardo's views, the Earth exists "at the centre of its elements" and resembles stars in the Cosmos. 
In one of the records of Leonardo da Vinci is mentioned the name of Argyropoulos - a famous Hellenist, a Greek professor closely associated with Marsilio Ficino and the Platonic Academy [3]. This convinces us that the ideas of Plato did not avoid the interests of Leonardo. And his passion for mythology, mystical symbols allows us to talk about reference to the method of philosophical allegories in his works, which is inherent in the style of Plato's dialogues "Republic", "Phaedrus", "Symposium". The very principle of the philosophical approach and the universal system of modelling the world penetrates into the essence of works of art. The proof is the statement of $\mathrm{G}$. Vasari that Leonardo "started a lot of works, but he never brought one to the end", as he was more interested in the philosophy of nature and "did not stop his fictions with the daily making of models and drawings." At the same time, he could achieve a lot in art, do not be "so multilateral and changeable, for he began to study many subjects, but, having started, then threw them" [4].

With the philosophical view of Leonardo, we come into contact in his approach to the subtleties of the primary perception of things, where he proclaims: "All our knowledge begins with sensations." But at the same time he strives in the works of art to the logic of inference, bringing the viewer to the concentration of the idea through figurative Eidos as a symbolic generalization. In artistic images Leonardo the philosopher proclaims justice as "the supreme law of nature, according to which reasonable harmony is established among all living on earth" [5]. The very purpose of art, in his opinion, does not reflect, but comprehend nature, while the best of the tools in the knowledge of the world is painting. On the basis of the principle of "reasonable harmony" is built a credo in the vision of the world of Leonardo, which later visibly incarnates in paintings. Painting is seen as the most concentrated way to reveal the depths of thought in a hidden imagery. In an open form, thoughts sound like philosophical ideas and can be interpreted as heretical in the context of this time and its religious canons.

The all-embracing views of the master are reflected in the unique accuracy of his pictorial and graphic handwriting, in the intersections of various themes, in artistic stylistics. In general, his work synthesizes artistic traditions from different epochs and styles: Antiquity, the Middle Ages, the Renaissance, reflects the origin of Mannerism, Classicism, Realism. At the same time, Leonardo da Vinci can be called the harbinger of the impressionistic approach, expressed in his works in the transmission of aerial perspective in landscapes. The artist's drawing has a special linear plasticity, masterfully accurately grasping the character and vital authenticity in different images. All the innovative ideas of Leonardo have emerged in creative works and theoretical reflections, generalizing practical experience. In general, the works clearly affirm the desire for a new expression in art, to search for new approaches to the knowledge of the world. In his art, Leonardo expresses the inherent combination of the breadth of spatial thinking and the ability to be specific in the psychologically accurate transmission of human states, which we can judge from portrait drawings. The inquisitive view of the master humanist demonstrates his manuscripts with recommendations to artists, as it is necessary to identify the characteristic in vital phenomena. Thanks to Leonardo's research approach, we receive today a small series of works of art, but maximally expressing his views as a philosopher and natural scientist. Therefore, the works require the same inquisitive view from the viewer: we need to look at them through the eyes of Leonardo himself, penetrating into the contexts of time and culture of the Renaissance. This is a view from the perspective of questions: "Why did the artist choose this way in solving the picture?" and "What is the meaning of each image in the picture?". Close 
attention to the images and familiarity with the recommendations of Leonardo da Vinci in the fine arts will help to reveal the sense of meanings in works. In the works, there is an interaction of images from different symbolic systems, where the crossing of the ancient and Christian traditions serves as the leading line. We see not the imitation of ancient forms with the purpose of deliberately changing the language of art, but a deeply conscious use of them. The artist fully breathed Antiquity into his creations, creating a visually and sensually alive movement in the pictures. An innovative approach is observed in the solution of composition, in the interpretation of artistic images and the renewal of pictorial techniques, including experiments with paints.

Let us pay closer attention to the sketch-painting called "Adoration of the Magi" (1481) from the Uffizi Gallery, which was especially difficult in the artistic-imaginative solution. Despite the fact that this is an unfinished sketch of the altar painting for the monastery of San Donato in Scopeto, the work captures key principles in the master's innovation, the views of Leonardo da Vinci, connected with the worldview principles of the Renaissance itself. "Adoration of the Magi" rightly can be attributed to the landmark works not only in the artist's work, but also in European art, since it contains symbolic content related to the historical, mythological and religious context. It is important that the work actualizes realistic trends in Italian art. Due to these qualities, "Adoration of the Magi" has an overall integrity: ideological, content and compositional. All these components need to be considered in detail in order to show its timeless uniqueness. It is important not to operate with abstract definitions, but to follow the path of forming the artist's intention, his successive steps. This is the way of scientific comparison, description, attraction of historical and cultural contexts. They are needed for the same experienced way, which was steadily followed by Leonardo da Vinci himself. At the same time, we turn to the interpretation of the symbolic images in the painting, which clearly belong to the cultural traditions from different historical eras.

The sketch "Adoration of the Magi" has a centric composition. Schematically it can be represented in the form of a triangular shape, which is typical for a number of works by Leonardo da Vinci. The unifying centre is the image of Mary with the infant Jesus. In this centring scene is brightly pronounced the theme of spiritual renewal, resolved through figurative metaphors. The realistic living solution in the movement of the body, hands and emotions of the Christ child attracts attention. Such activity in the movements of infants is also seen in the works of Leonardo da Vinci - "Madonna Litta" and "Benois Madonna" where the small hand of Jesus touches the little goldfinch or reaches for the flower: the theme of harmony, unity of the divine in man and nature. Not without reason in live subjects with images of babies, researchers note the earthly mother's joy that Leonardo gives sublimely and solemnly. Therefore, the image of Heaven in works sounds in a special way, like the universal cosmic power, as a symbolic sign of the divine significance of real earthly happiness and prosperity.

In the upper part of the "Adoration of the Magi" two scenes are drawn: on the left, there is an image of a dilapidated ancient temple and on the right is a battle of horsemen. In the first subject, the temple shows us a connection with the traditions of Antiquity, with its new rise, with its visibly reviving history. This is indicated by the triumphal flight of horses, a rider and soaring female figures. The scene clearly symbolizes the entry of the ideas and artistic traditions of the ancient era in the culture of the Renaissance time. It is a meeting of two epochs, bringing revival and renewal. In the right upper part of the sketch in a dynamic perspective is shown a different in spirit scene: the battle of two militant horsemen as two opposing forces. In the battle with the rearing horses and 
defeated people, the artist anticipated another masterpiece - "The Battle of Anghiari": the largest fresco, created later in 1506, and incomplete. It has become an excellent educational model for artists in anatomy in cases of images of masterly plastics of figures. In two works one thought is conveyed: the horror of war and the fight against a brutal confrontation, as the frightened eyes of horses express the most emphatically, the furious turn of their heads. The scene points to the pernicious nature of wars, conquests and all sorts of oppositions that carry evil. It sounds like a prophetic warning for people from Leonardo da Vinci. The background for this scene is the mountains, which, according to ancient mythology, turn us to the Cosmos as a symbol of the universal world order. The idea of harmony of the Cosmos was fundamental in the views of people in the period of early Antiquity. On the far mountain on the right is hardly visible the image of an elephant, that since ancient times has been a symbol of prosperity, reliability and strength. In our view, it is the traditionally approved by humanity idea of reasonable harmony and stability in the world, that tried to convey in his works Leonardo.

So, in the two upper scenes of the Adoration of the Magi, Leonardo's wise thought leads us to an understanding of how human energy is able to carry a creative power and the opposite one, capable of destroying life itself. The lower level of the picture concentrates the key pictorial and semantic load: it is a scene with images of the Magi, John the Baptist and multiple images of people participating in an important event: the first appearance of Christ in the world of people. Above the image of Mary are two trees of David, and between them appears a horse. Based on the semantics of the ancient symbols, the tree is the Tree of Life, the sacred sign, the symbol of fertility and integrity, wisdom and prosperity, and in Christianity means the Renaissance, the Cross of Redemption. This symbol exists outside of time, in the context of different cultures and religions. The image of the central horse reinforces the significance of the image of the Tree, filling the content with the meaning of Power and Perfection. Further, the symbol is amplified by a rhythmic representation of the heads of horses, located on both sides of the centre. The horse was often depicted in ancient art, including Antiquity, and was closely related to both mythological subjects and real events from history. In the Renaissance, horses are often present in religious subjects and battle scenes. It should be noted that in the work of "The Adoration of the Magi", Leonardo da Vinci figuratively combines several time periods, that is, makes simultaneous events from Antiquity (the appearance of Helios with a chariot), Christianity, which unites symbolic and ancient Christianity (the very event of the birth of Christ and the adoration of the Magi) and the Middle Ages (the images of the priests depicted on the left), the Renaissance (the image of Leonardo da Vinci himself on the right). The work unites timeless events and symbols: the battle as a symbol of confrontation, the knight, the tree, the ladder are the connecting symbols - this is the path of a new ascent, the Renaissance renewal, the symbols of the connection of different epochs. As a whole, behind this symbolic complex lies the connection between different cultural traditions, the combination of the real and the conditional.

However, there is a version of the bioengineer and art historian Maurizio Seracini, nominated in 2001, that the work "Adoration of the Magi" in Ufizzi has two options. One of them is hidden under a colourful layer and really belongs to the hand of Leonardo da Vinci, and the upper sketch was painted by another artist who moved away from the original sketch with a distortion of Leonardo's true intentions. It can be assumed that the unknown artist tried to translate the theory about the importance of the 
correlation of light and shadow, which Leonardo da Vinci himself developed in the recommendations for artists. But, if we compare the two sketches of the "Adoration of the Magi" from the Uffizi and Louvre museums, then there is certainly a similarity between them in compositional construction, the plasticity of linear solutions. If the colour layer violates the artistic approach of Leonardo da Vinci, then it enhances the realistic task of conveying the psychological interpretation of images. Nevertheless, the clear location of different subject-parts in the picture is obviously preserved by the author.

In general, this multi-layered in its structure work is represented by: 1) a number of interrelated subjects with complex multi-figure scenes, each of which could be an independent work; 2) the multilayer is determined by a different graphic interpretation; 3) a complex ideological concept. The artist works masterly with line and spot in combination from dark to light. The subject is based on the contrast in accordance with the imaginative decision. The artist creates a system with iconic images and religious attributes. The volumetric-spatial approach essentially distinguishes the artisticfigurative stylistics of the Renaissance from the style of the Middle Ages. The world of objects, animal beings and the human body is freed from attachment to the plane, go into an open spatial movement, striving for expansion and freedom of action. The theme of spiritual renewal is conveyed through contrast in depicting people: the ideological opposition of images is achieved by the power of persuasiveness of characters, the difference of psychological states with different attitudes toward the appearance of Jesus.

The very image of Jesus, with its naturalness in motion, sounds like an earthly one and, in the context of the work, appears as a symbol of a new attitude to the world, which gives a message to a new understanding of the human destiny. There is a reduction of the previously formed idea of the entirely "vertical" subordination of man to God to the new: the unity of the divine and the human, where the creative mission of man on earth as the given from above is the divine mission. This idea is compositionally marked in the central scene, where the images of Mary and Jesus are organically solved. They integrally unite and hold all the content, all the additional subjects of the work.

One of the central images in the "Adoration of the Magi" - John the Baptist, is a historical figure and the predecessor of Jesus Christ, who predicted the appearance of the Messiah. As a preacher, transmitting the will of God, John the Baptist called people to repentance, respectively, the image of John the Baptist was realized in the traditional solution. The right hand with the finger pointing upwards is a call to repent and at the same time a message about the approach of the Kingdom of God. From his mouth sounded the call: "Repent, for the kingdom of heaven is near. The axe lies ready at the root of the trees, and every tree that does not produce good fruit will be cut down and thrown into the fire." [7]. In another work called "John the Baptist" (1513), Leonardo da Vinci depicts the Baptist on the background of a large rock. The rock traditionally in religious subjects symbolizes the place of asceticism and replaces the image of "hills", and at the same time means the elevation of the mind and spiritual purification in the upper world as the divine. With a close look at the rock, appears a part of the head, at first sight, of an strange being. In fact, this is Lamb of God - the symbol of John the Baptist himself. John the Baptist was depicted with a cross-staff in the form of a reedthin trunk in his hand, and, as a rule, a lamb - attribute of John the Baptist was depicted nearby. A similar subject we find in the work of Titian. In the general, the image of John the Baptist of Leonardo da Vinci marks anthropogenic features inherent in the art 
of this time. The work clearly manifests tendencies of Mannerism - the style that has been developed in the further development of art.

The "Adoration of the Magi" clearly presents a multi-component structure, where the interconnection of one scene after another logically leads the attentive viewer to understand the artist's main intention. The principle of contradiction, opposition and affirmation of the sublime spiritual are interpreted through a complex storyline in the work. It is reflected in the subject philosophical view of Leonardo da Vinci answers the questions related to the artist's retreat from the traditions and the approval of new techniques in the visual arts. In his search for truth and perfection, Leonardo da Vinci, first of all, follows Plato, putting these qualities into works of art, namely in painting, considering it the highest creation. According to Plato's definition, Eidos (ideas) are true Being ("solar world") [6]. The desire of Leonardo da Vinci to the ideal, to the content filled with Eidos, makes his painting mystical, mysterious and vital at the same time. The ideas order space in the picture and fill it with meaning. We can assume that the work of Leonardo da Vinci, his works of art are a picturesque formula of the ChristianPlatonic ideas of the Academy. The logic of imagery in the "Adoration of the Magi" of Leonardo da Vinci follows the allegorical symbols created by Plato in the dialogues. Let us try to reveal it in more detail. Thus, in the work "Republic" Plato creates a myth about the Cave, in the image of which appears a dual world: on the one hand, it is a world of matter, unstable and imperfect, and, on the other, a potential world for the formation of ideas. A symbol of the cave in the "Adoration of the Magi" is the crowd of people surrounding Mary and Jesus. This scene vividly conveys to us the strength of internal contradictions that have engulfed all those present at the event. The theme of human emotions, and, accordingly, attitudes towards the appearance of the Messiah: some individual images have shining faces, the others are frightened. According to Plato's allegory, the image of the flying chariot in the left upper part of the picture is represented in the "Phaedrus" as a kind of human soul, where the charioteer is her higher, reasonable incarnation. In the context of the picture, this image symbolizes the breakthrough of the soul beyond the cave world, its emergence into a transcendent level, into the sphere of acquiring spiritual forces for man. A similar theme also sounds in the image of the Stairs, which, according to the "Symposium" dialogue, that tells of two types of Eros, earthly and heavenly, also acts as a symbol of the ascent of a feeling of love for the divine transformation of man, for highest being and perfection. This is the Stairs of spiritual ascent and renovation - the main idea of the work of Leonardo da Vinci.

\section{CONCLUSIONS}

In "The Adoration of the Magi" the philosophical theme of human rebirth, his spiritual awakening and renewal, has become a key one. This idea is subordinated to the completely imaginative system: from symbolism to complex subject compositions, linking mythology, Antiquity, the Middle Ages and the Renaissance. Leonardo da Vinci's concept looks far into the future, wanting to see a person as freethinker and creator, what was the artist himself. Leonardo da Vinci appears here vividly as an artist-philosopher, thinker, and in all ways of artistic and imaginative solution seeks to embody the intended meanings in the work. As a result, the study of Leonardo da Vinci's creativity and the work "Adoration of the Magi," is ordered a system of symbolic content, revealing the artist's appeal to ancient symbol images, to the use of allegory, consonant with ancient myths and the method of Dialogues of Plato. The 
works of Leonardo da Vinci show us the synthesis of artistic styles from different time periods: Antiquity, the Middle Ages, the Renaissance, the origin of Mannerism, Classicism, Realism. All these qualities serve as a kind of vector in the art of the Renaissance and the future. All artistic, stylistic and symbolic techniques are directed by the master to the embodiment of the basic idea: spiritual ascent and human renewal.

\section{REFERENCES}

[1] Dobrokhotov A.L. Teleology of Culture, Russia, p. 38, 2016.

[2] Zubov V.P. Leonardo da Vinci, Russia, p. 115, 1961.

[3] Leonardo da Vinci. Selected works, vol. 1, p. 20, 2012.

[4] Leonardo da Vinci. Selected works, vol. 2, p. 20, 2012.

[5] Leonardo da Vinci. Fairy tales, legends, parables, Russia, p. 20, 1983.

[6] Ryabov P. Culture of Ellada, Russia, p. 460, 2017.

[7] The Gospel of Matthew chapter 3:10. 